\title{
A ATUAÇÃO DO PROFISSIONAL DE RELAÇÕES PÚBLICAS DENTRO DO PROCESSO DE COMUNICAÇÃO PÚBLICA, POR MEIO DAS MÍDIAS SOCIAIS, DA PREFEITURA MUNICIPAL DE CURITIBA
}

\author{
Alana Fernandes Franco ${ }^{1}$ \\ Tatiane Pavan ${ }^{2}$ \\ Ana Paula da $\operatorname{Rosa}^{3}$
}

\section{Resumo}

Este artigo foi elaborado com o objetivo de analisar a atuação das relações públicas no processo de comunicação pública, realizado pelas mídias sociais, do órgão público Prefeitura Municipal de Curitiba. A metodologia de pesquisa utilizada neste estudo foi à análise de conteúdo disponibilizado na web, especificamente nas mídias sociais.

Palavras-chave: Comunicação pública, Prefeitura Municipal de Curitiba, Comunicação digital, Mídias sociais, fanpage.

\begin{abstract}
The aim of this article is to analyze the development of public relations in the process of public communication held by the city hall of Curitiba with the use of social media. In this study, as a methodological basis, we use the analysis of the content available on the internet, mainly in social media. Keywords: Public communication, city hall of Curitiba, digital communication, social media, fanpage.
\end{abstract}

\section{Introdução}

A comunicação é um processo de contato e interação entre os indivíduos. Em uma organização, a comunicação desempenha a função de administrar o fluxo de informações em todo o ambiente empresarial e, principalmente, garantir a eficácia do relacionamento entre a organização e seus públicos, além de melhorar o nível de percepção, divulgar acontecimentos, eventos e ideias. Tal processo na comunicação pública necessita de aprofundamento em seus estudos por estar diretamente ligado a fatos históricos e em constante mudança. A comunicação

\footnotetext{
${ }^{1}$ Graduada em Comunicação Social - Relações Públicas pela Pontifícia Universidade Católica do Paraná. E-mail: alana.ffrancog@gmail.com.

${ }^{2}$ Graduada em Comunicação Social - Relações Públicas, pela Pontifícia Universidade Católica do Paraná. E-mail: tatiane.pavan@hotmail.com.

${ }^{3}$ Doutora em Ciências da Comunicação (Unisinos). Professora do Programa de Pós-graduação da Universidade do Vale dos Sinos (Unisinos). Email: anarosa208@ yahoo.com.br.
} 
pública está diretamente inserida na área administrativa das instituições públicas, sendo necessário mostrar sua relevância para aprimorar a relação entre Estado e comunidade.

As atividades de relações públicas começaram a se desenvolver no Brasil em 1964 e, com isso, se tornou comum a prática de assessoria de comunicação, e suas atividades atraíram muitos interessados. Em 1968, a profissão de relações públicas foi regulamentada, tornando-se uma área de estudo da comunicação. No mesmo ano, o governo militar começou a censurar a imprensa e ao mesmo tempo criou a Assessoria Especial de Relações Públicas da Presidência da República (AERP) com o objetivo de divulgar para a mídia e a população as "verdades oficiais", começando então a difundir a profisssão a partir do funcionamento da comunicação dentro de uma instituição pública.

Portanto, o tema desse artigo é a atuação do profissional de relações públicas dentro do processo de comunicação pública, por meio das mídias sociais, da Prefeitura Municipal de Curitiba. Com isso, o objetivo geral do estudo é analisar a atuação das relações públicas no processo de comunicação das mídias sociais dentro do órgão público Prefeitura Municipal de Curitiba. Os objetivos específicos são: verificar a função do profissional de relações públicas no processo de comunicação da Prefeitura de Curitiba, especificamente nas mídias sociais; e o planejamento das suas atividades de interação com os cidadãos para análise dos resultados. Além disso, busca-se entender o funcionamento da comunicação pública pela ótica das mídias sociais.

A realização do estudo sobre a comunicação pública se mostra pertinente porque é uma área de interesse do profissional de relações públicas, e está em constante crescimento. Esta área, com o passar dos anos, está passando por significativas mudanças onde se torna perceptível a importância de haver profissionais especializados em relações públicas para atuar estrategicamente como articulador no processo comunicacional da instituição.

\section{Comunicação pública}

Comunicação pública é o processo comunicativo realizado entre o Estado, o governo e a sociedade, com o objetivo de informar para a construção da cidadania. O termo atualmente substitui denominações utilizadas para a comunicação dos órgãos governamentais, como comunicação governamental ou comunicação política. Uma análise do uso da expressão comunicação pública desde o início do século XX mostra que o conceito esteve relacionado com a comunicação estatal e a implantação da radiodifusão, e, mais tarde, da televisão pública. Enquanto a imprensa tradicional se desenvolveu regulada pelas forças políticas, culturais e de 
mercado, os meios eletrônicos necessitavam ser autorizados e regulados por concessão pública (MATOS apud DUARTE, 2007, p. 49).

Essa expressão vem sendo usada no Brasil desde a década de 70, quando se começou a discutir direito e políticas de comunicação. Porém, o termo ganhou força no início da década de 80 quando a Frente Nacional de Luta pela Democratização da Comunicação, movimento civil que congregou entidades profissionais e intelectuais, pretendia apresentar propostas de políticas de comunicação à Constituição Federal.

O conceito de Comunicação Pública relaciona-se com a compreensão do bem público, implica uma prática para a democracia e a construção da cidadania. É um conceito que supõe um posicionamento político, diferente do partidário.

\section{Comunicação na administração pública}

É direito de todo cidadão ter acesso à informação, principalmente advinda de órgãos públicos, como assegurado na Constituição Federal de 1988. Porém, o Estado não se preocupa em criar canais de comunicação claros e abertos, para que a população tenha livre acesso.

A constitucionalidade, a participação e a escolha racional, podemos perceber sobretudo através das duas últimas, que acentuam a importância de um público informado e educado - como a comunicação é de maior importância para determinar como os governos e a oposição comunicam com o público (SILVEIRINHA, 2008, p. 14).

Cabe ao Governo, então, adotar uma política de portas abertas, oferecendo ao cidadão o direito de conhecer e participar da Administração Pública, desenvolvendo assim um vínculo com a população, priorizando a transparência das informações.

\footnotetext{
As estruturas de comunicação na administração pública federais hão de se reorganizar em função de evolução dos conceitos e das novas demandas sociais. Os profissionais precisam ser especialistas nas respectivas áreas e setores, devendo, mesmo assim, ter noção completa de todas as atividades e programas. Os modelos burocráticos de gestão estão ultrapassados. O dinamismo, a mobilidade, a agilidade a disposição são os valores que deverão balizar as estruturas. (TORQUATO, 2002, p. 121).
}

As informações têm o poder de se transformar cotidianamente, é preciso que os profissionais ligados a está área sempre se mantenham em constante evolução para que possam assim ajudar na reorganização e atualização da comunicação pública. 
A partir da década de 80 , com a Constituição de 1988, a criação e legitimação de novos direitos e deveres dos cidadãos, a força dos movimentos sociais e o desenvolvimento tecnológico formaram um sistema de participação e pressão política, o que influenciou na criação de mecanismos para atender às exigências de informação e tratamento justo por parte do cidadão em sua relação com o Estado e instituições. (DUARTE, 2007, p. 23).

No âmbito do terceiro setor, as ações têm caráter benemérito e de emancipação cidadã. Estas são centradas no compromisso com a redução das desigualdades, de modo a resolver, ou pelo menos, amenizar problemas graves que afetam grandes segmentos populacionais (PERUZZO apud DUARTE, 2007, p. 161). Nesse cenário, a Comunicação Pública passou a ser uma estratégia de força, tanto para o terceiro setor, pois facilita o acesso à administração pública, quanto para o governo, que passou a estar mais presente no dia a dia da população. A comunicação é uma das áreas mais importantes para a vida de uma organização, entretanto, para garantir tal sobrevivência no ambiente de interesse público, além de administrá-la de forma adequada, é necessário atender ao direito do cidadão de ter capacidade de agir em seu próprio interesse.

O termo comunicação pública tem sido compreendido como sinônimo de comunicação governamental, por ter sua origem ligada a ela. Compreende-se então um processo comunicativo das instâncias da sociedade, que trabalham com a informação voltada para a população. O conceito de comunicação pública vem sendo incorporado ao vocabulário dos profissionais da área, sobretudo ligado à comunicação governamental. Matos e Brandão fazem uma releitura dos conceitos e apresentam uma versão que congrega os principais pontos, que são: a participação do Estado, do Governo, da sociedade e do Terceiro Setor, a localização na esfera pública e a fundamentação no interesse público.

Matos define Comunicação Pública com democracia e cidadania e pensa a Comunicação Pública “como um campo de negociação pública, onde medidas de interesse coletivo são debatidas e encontram uma decisão democraticamente legítima". Na mesma direção, Brandão define Comunicação Pública como o processo de comunicação que se instaura na esfera pública entre o Estado, o Governo e a sociedade e que se propõe a ser um espaço privilegiado de negociação entre os interesses das diversas instâncias de poder constitutivas da vida pública do país.

Segundo Duarte (2006, p. 2), a comunicação pública ocorre em um ciclo (figura 1) de informações de interação entre agentes públicos e atores sociais em temas de interesse coletivo, tratando de compartilhamento, negociações, conflitos e acordos na busca do atendimento de interesses coletivos. Diz respeito também ao aparato estatal, as ações governamentais, partidos políticos, terceiro setor e, em algumas ocasiões, às ações privadas. Diz ainda que a Comunicação Pública tem como objetivo a viabilização do direito social coletivo e individual ao diálogo e à informação. 


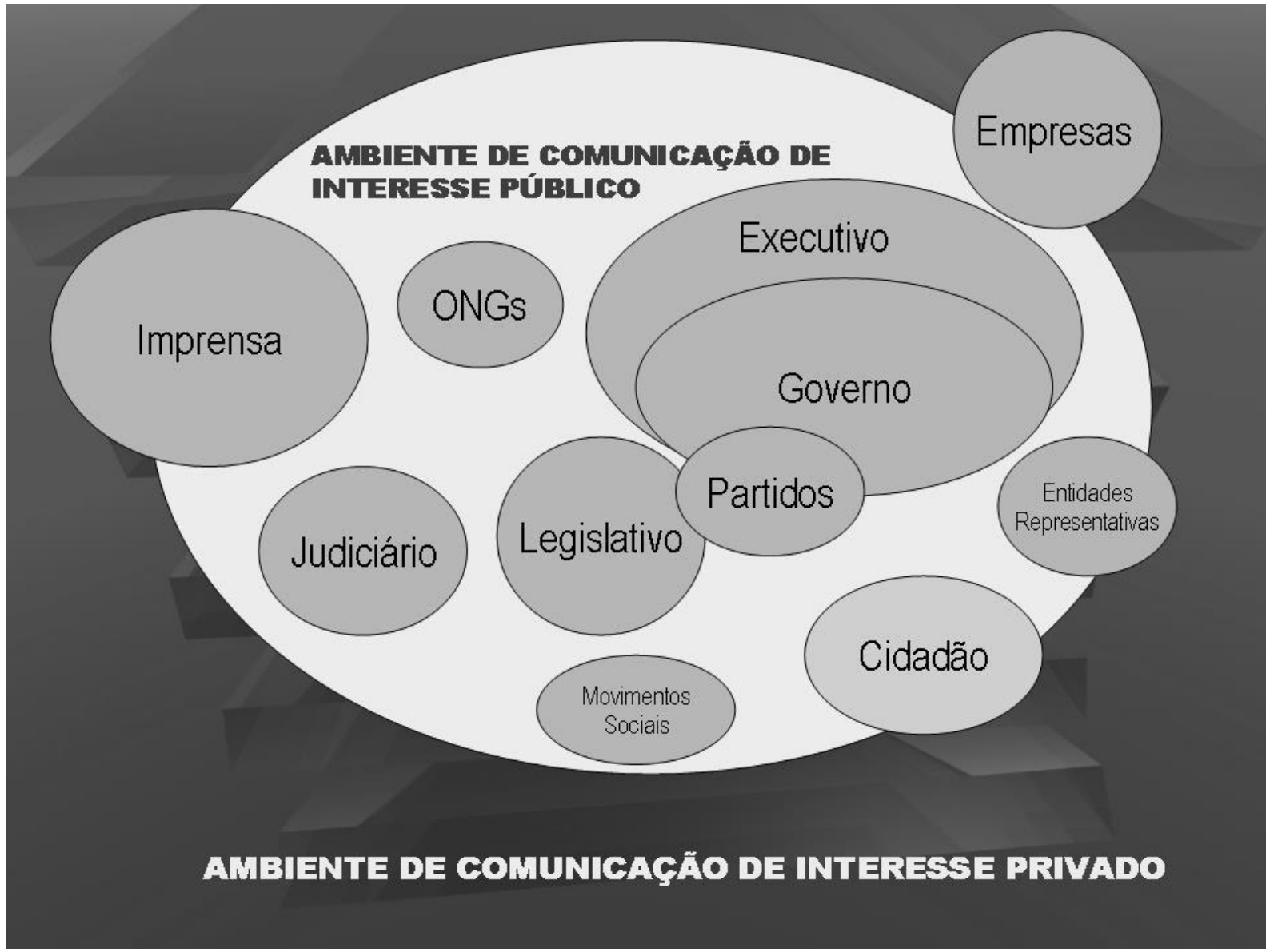

Figura 1 - No desenho acima está a proposta de modelo de campo da comunicação pública, com a distinção de alguns dos principais atores. Dentro do círculo estão os atores cujas ações e comunicações necessariamente dizem respeito ao interesse coletivo. Imprensa, cidadão, entidades representativas e empresas praticam ações e comunicações de natureza privada e também de natureza pública. Fonte: DUARTE, 2006, p. 2.

O papel da comunicação não é de apenas produzir e transmitir informações, é fazer circular, criar uma via de mão dupla e é um componente que busca a negociação entre os interesses do Estado e a sociedade, denominado Comunicação Pública, que tem a finalidade de organizar a voz do cidadão no cenário político.

\section{Relações públicas governamentais}

A população de um país, estado ou município é ao mesmo tempo usuária dos serviços públicos, eleitora de seus administradores e contribuinte do orçamento onde está inserida. Estes elementos caracterizam a população como receptora e emissores do processo político e do processo de comunicação existente entre governo e sociedade. Uma das formas de mediar esta relação são as relações públicas governamentais. As estruturas dos governos, em nível federal, estadual ou municipal, devem ser profissionalizadas. Em primeiro lugar, tais estruturas devem 
possuir profissionais qualificados. Depois, precisam trabalhar com produtos bem delineados nas áreas de comunicação jornalística, editoração, relações públicas, propaganda, pesquisa, articulação com a sociedade, eventos (TORQUATO, 2002, p. 84).

Governantes devem estar sempre informados sobre seus governados, que por sua vez devem buscar informações sobre o governo de seu município, estado ou país. Essas informações devem estar acessíveis a todos. Se a população não tem consentimento do que está sendo feito pelos governantes, pode não entender a dinâmica das atividades desenvolvidas, nem interferir nelas, de modo a participar destas e até mesmo fiscalizá-las. Para Andrade (1982, p.85), o Poder Público, quanto mais souber sobre seus públicos, maiores oportunidades terão para tomar decisões em harmonia com suas atitudes.

Para a Administração Pública é muito importante o levantamento, a análise e a crítica das suas próprias condições internas, bem como conhecer, com a possível exatidão, o "universo" de sua atuação. [...] O conhecimento dos fatos, interna e externamente, por parte dos governantes, deve constituir-se em meta de interesse prioritário na Administração Pública (ANDRADE, 1982, p.85).

O fluxo de informações se faz necessário em todos os segmentos. No âmbito governamental, quanto mais informações o povo tiver sobre o governo, maior participação terá nos processos e atividades deste. Para Andrade (1982, pág. 84) “[...] o Poder Público depende do consentimento e da participação do povo na execução das diretrizes governamentais".

O objetivo de estabelecer um fluxo de informações contínuas sobre as atividades da administração como proposta estratégica para as relações públicas implicitamente abrange duas dimensões que precisam ser exploradas. A comunicação entre governo e sociedade não deve ser inconstante ou sofrer interrupções, para ser eficiente ela deve ser regular e constante a fim de transmitir segurança à população de que a informação, sempre que for preciso, será transmitida, possibilitando a transparência e publicitação das ações de governo (NOVELLI, 2009).

Relações públicas governamentais são o esforço deliberado, planificado, coeso e contínuo da alta administração pública, para estabelecer e manter uma mútua compreensão entre governantes e governados, ou seja, um diálogo planejado e permanente, que procura determinar interesse social. É preciso que as estruturas trabalhem com um conceito sistêmico de comunicação evitando disparidade da linguagem. Observa-se que o setor de relações públicas, às vezes, está distanciado da área de imprensa, que, por sua vez está afastada da 
editoração e da publicidade, e assim por diante. A estrutura deve ter comando único para preservar a harmonia das linguagens (TORQUATO, 2002, p. 84).

As ações de relações públicas governamentais devem buscar estimular a participação da população nos atos da administração pública, como por exemplo, dar voz a essa população, podendo, assim, se expressar sobre o governo sem receios, para que essa expressão sirva com uma oportunidade de negociação para ambas as partes.

Para tanto, o profissional de relações públicas pode atuar de diversas formas. Deve primeiramente fazer um diagnóstico detalhado da comunidade em questão, e pontuar estratégias e instrumentos adequados, para que governo e cidadãos possam se entender. Isto porque o importante em um programa de relações públicas governamentais está na sinceridade das informações, pois o governo deve dizer tudo o que fez, inclusive seus erros e as medidas que foram tomadas para corrigi-los (ANDRADE apud COLLARO, 2005, p. 38).

Além disso, cabe ao profissional de Relações Públicas implementar a visão do exercício da cidadania em tudo o que fizer, pois não basta criar meios para que a população participe, é necessário entender profundamente a importância obtiva pelos cidadãos.

\section{Relações públicas comunitárias}

Desde o fim da década de 80 ouve-se falar em comunicação popular e comunitária. Os termos se estendem às relações públicas ao se tratar da participação do povo nos processos democráticos, tendo-o como protagonista. Para Peruzzo (2006, p. 4), ambas as definições de comunicação podem ser entendidas de diversas formas, mas sempre com uma denotação de "povo" como ator principal e como destinatário. Fala ainda que: “[...] comunicação comunitária se caracteriza por processos de comunicação baseados em princípios públicos, tais como não ter fins lucrativos, propiciar a participação ativa da população, ter propriedade coletiva e difundir conteúdos com a finalidade de educação, cultura e ampliação da cidadania" (PERUZZO, 2006, p. 9).

Os princípios das relações públicas comunitárias são de transformar a sociedade, atuar em busca do interesse coletivo e atingir a evolução da comunidade, tendo como finalidade promover a cidadania a todos. Longe de propor uma revolução ou "luta armada", as Relações Públicas Comunitárias buscam o estabelecimento de canais mais verdadeiros de integração, para que o público seja realmente cidadão da comunicação. É fundamental, neste sentido, que o profissional de relações públicas perceba-se como sujeito da história a serviço do coletivo e 
não como agente de criação de projetos para atender a fins individuais (ESCUDEIRO, 1999, p. 87).

A construção da cidadania é fator fundamental para as Relações Públicas Comunitárias. Afinal, é com base nisso que a profissão busca agir nos diversos grupos sociais, principalmente em comunidades de baixa renda, agregando valores civis, políticos e sociais. Rubim (1998, p.189) explica que há um descompasso entre a definição formal de cidadania e sua prática efetiva, dentre os maiores obstáculos estão a desigualdade social e a concentração de poder. Além disso, deve-se atualizar o conceito, tratando de assuntos como o direito à cidadania planetária (em espaços globais) e o direito à cidadania midiática (espaços eletrônicos).

Nesse processo de reaprendizado da cidadania, a comunicação é vista como ponto de partida. Pois comunicar-se é um direito de todo cidadão, não se limitando a receber apenas a mensagem, e sim se manifestar e ser ouvido, tornando-se, então, um emissor sujeito ativo em todas as fases do processo de comunicação. Se a democracia é compreendida num sentido restrito, de regime político, o significado atribuído à cidadania está relacionado aos direitos civis e políticos. Num sentido amplo, como forma de sociabilidade, a cidadania adquire novas dimensões, englobando os direitos sociais e os direitos humanos (MAGALHÃES, 2003, p. 177).

Cabe ao profissional de relações públicas participar da comunidade como agente, deve estar preparado para encarar os problemas e agir com sinceridade, sem querer apenas fazer a imagem positiva da organização que representa, deve estar preparado para a realidade social, afinal, se a empresa estiver fazendo alguma coisa que prejudique a comunidade, cabe ao RP providenciar medidas e soluções para o problema. E os profissionais de relações públicas, até enquanto cidadãos, com seu saber especializado, podem dar sua parcela de contribuição na construção de uma sociedade que supere a degradação humana e a desigualdade social e desenvolva uma cultura democrática e a própria democratização econômica, política e cultural (PERUZZO, 2004, p. 11).

As Relações Públicas Comunitárias possuem na comunidade um forte canal de atuação. "Uma das mais recentes e importantes mudanças nas atividades de administração para com as relações públicas tem sido o amplo reconhecimento de que as verdadeiras relações públicas começam no nível da comunidade” (ANDRADE, 1994, p. 80).

A construção da cidadania é o objetivo primordial das Relações Públicas Comunitárias. É diante desta problemática que a profissão procura agir inserida nos diversos grupos sociais, na maioria dos casos, em comunidades que possuem baixa renda socioeconômica. 
O conceito de cidadania agrega valores dos direitos civis, políticos e sociais e é necessário conceituá-lo para que a finalidade das Relações Públicas Comunitárias possa ser compreendida em sua totalidade e, a partir disso, os conceitos teóricos da profissão pontuados. Em princípio, cidadania refere-se aos direitos e às obrigações nas relações entre o Estado e o cidadão. Falar em cidadania implica recorrer a aspectos ligados à justiça, direitos, inclusão social, vida digna para as pessoas, respeito aos outros, coletividade e causa pública no âmbito de um Estado-nação (KUNSCH, 2007, p. 63).

Os conceitos teóricos das Relações Públicas Comunitárias são desenvolvidos a partir da definição teórica de cidadania e comunidade, e aprofundados, paralelamente, aos conceitos existentes de Comunicação Comunitária. Peruzzo (2006, p. 2) define comunicação comunitária diante do termo comunicação popular:

\begin{abstract}
A comunicação popular foi também denominada de alternativa, participativa, horizontal, comunitária e dialógica, dependendo do lugar social e do tipo de prática em questão. Porém, o sentido político é o mesmo, ou seja, o fato de tratar-se de uma forma de expressão de segmentos excluídos da população, mas em processo de mobilização visando atingir seus interesses e suprir necessidades de sobrevivência e de participação política. No entanto, desde o final do século passado passou-se a empregar, mais sistematicamente, no Brasil, a expressão comunitária para designar este mesmo tipo de comunicação e também outras expressões similares.
\end{abstract}

A comunicação comunitária trabalha com os grupos excluídos da população, os quais estão em processo de mobilização, a fim de suprir necessidades de sobrevivência e de participação política dos mesmos. As Relações Públicas Comunitárias também trabalham com esse público com estratégicas específicas. Porém, ambos necessitam da participação dos grupos mobilizadores para alcançar seus objetivos.

\title{
Comunicação e mídias sociais
}

Hoje, a comunicação não pode mais ser estudada como no passado, baseada apenas em livros e teorias. Cada vez mais a prática cotidiana incide sobre os modos de pensar, ver e fazer a comunicação. A comunicação digital e as redes sociais estão ampliando a maneira de se comunicar, utilizando ferramentas que facilitam o acesso de todos à informação e que permite relacionar-se com outros usuários da mesma rede.

Inserido no contexto desta nova comunicação surgiram os sítios de redes sociais, com o intuito de facilitar a interação social com ajuda do computador. Segundo Christopher Barger (2013), a mídia social é: "Um ambiente no qual as barreiras para a publicação de dados desapareceram, transformando qualquer pessoa que possua uma boa conexão de Internet em um editor em potencial e, por conseguinte, em uma fonte confiável de informações". 
Uma ferramenta aberta a todos os públicos, que possibilita opinar sobre um determinado assunto, acessar notícias e fatos, compartilhar o que é de interesse próprio e utilizar as informações dispostas na rede. Em 1996, surgiu o primeiro programa de mídias sociais com a finalidade de criar um local de bate-papo online, o I seekyou (ICQ). Um ano depois, em 1997 a AOL lançou o instant Messenger (AIM), e ambas as ferramentas possuíam a opção de criar "listas de amigos" e, também, selecionar os contatos por categoria, por exemplo: trabalho, escola, família.

A comunicação online continuou a vivenciar inovações ao passar dos anos, podemos analisar na figura abaixo a genealogia das redes sociais e suas mudanças.

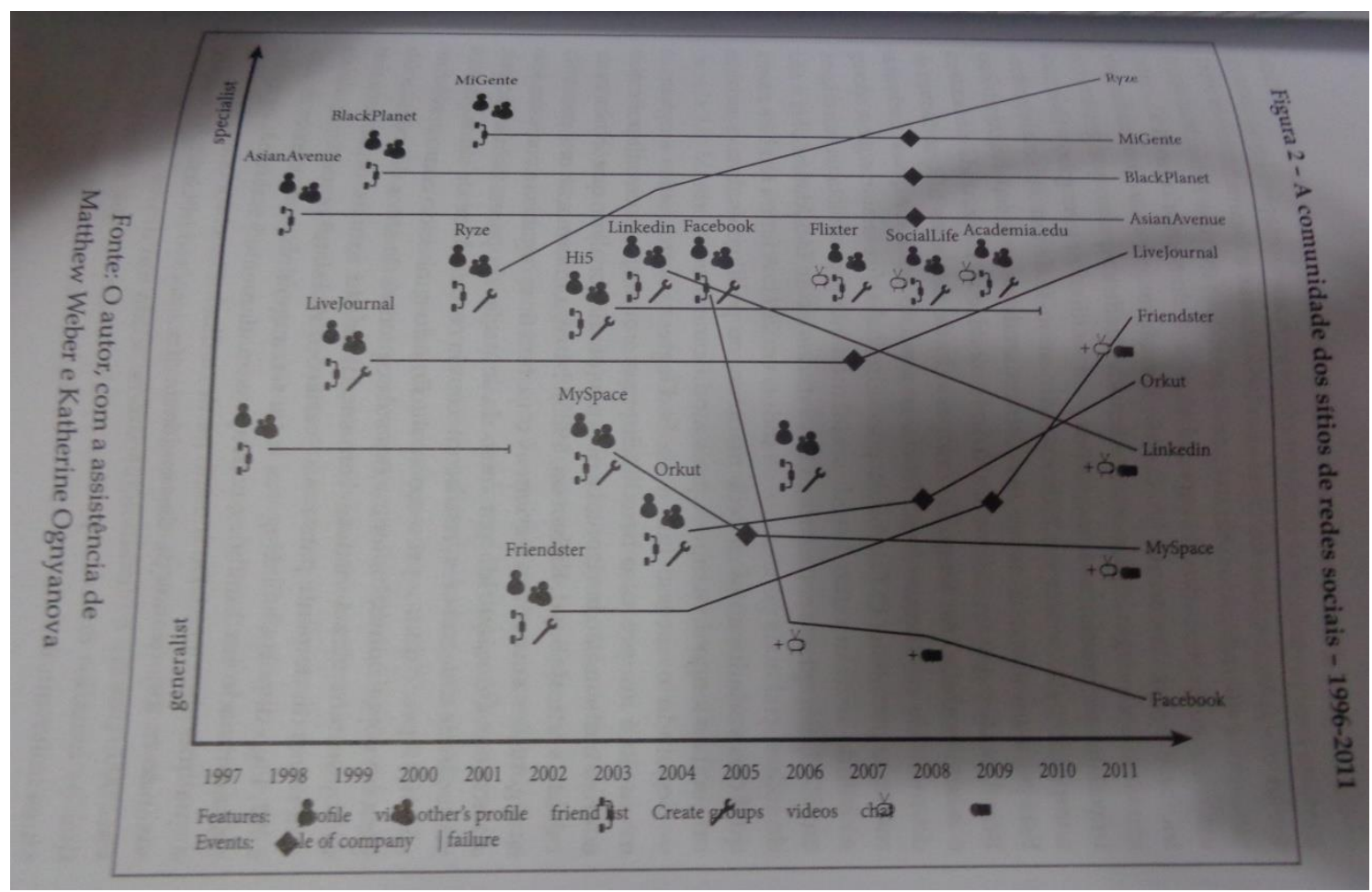

Fonte: O autor, com a assistência de Matthew Weber e Katherine Ognyanova - Livro Redes sociais, comunicação, organizações.

A figura mostra o surgimento das redes sociais, o caminho que as mesmas percorreram ao passar dos anos, as empresas concorrentes que surgiram no mercado ao longo destes anos, além daquelas que acabaram sendo esquecidas e substituídas por outras mais atuais. Utilizando por base uma pesquisa realizada para a Abracorp, em 2011, podemos identificar quais ferramentas de mídias sociais são as preferidas dos usuários naquele momento. Em primeiro lugar aparece o Facebook (93\%), em seguida oTwitter (89\%), Youtube (64\%), Orkut (59\%), Linkedin (54\%) e blogs (51\%). 
Com o avanço da tecnologia da informação e o surgimento das mídias sociais a atividade de relações públicas buscou se modificar para melhorar a relação entre o seu público e os comunicadores.

\begin{abstract}
As mídias sociais estão no centro das atenções, todos possuem voz e podem ganhar a atenção e, quando ganham, essa voz na rede pode influenciar fortemente as empresas, fazendo com que revejam, por exemplo, a sua estratégia de produto ou de Marketing. (INAGAKI, 2012, p. 56)
\end{abstract}

Com as mídias sociais qualquer pessoa, independente da sua profissão ou classe social, pode se expressar livremente, criar uma lista de amigos e se comunicar de maneira rápida e eficaz, sem precisar se locomover. Esta ferramenta veio para auxiliar o processo de comunicação e facilitar o trabalho dos profissionais de comunicação, pois com mais canais de comunicação fica mais fácil veicular fatos.

\title{
Estudo da Prefeitura Municipal de Curitiba
}

Como objeto de estudo das práticas administrativas, governamentais, comunitárias e públicas, vamos utilizar as mídias sociais da Prefeitura Municipal de Curitiba para demonstrar e analisar as estratégias desenvolvidas pela comunicação deste órgão público no relacionamento com a comunidade. Dentro da esfera da comunicação pública, o tema proposto é uma das áreas de atuação do profissional de relações públicas e estabelece um papel significativo entre o órgão e a comunidade. Como metodologia de pesquisa utilizamos análise de conteúdo na web, tendo como corpus as mídias sociais para monitoramento.

A cidade de Curitiba foi fundada em 29 de março de 1693, pelo capitão-povoador Matheus Martins Leme ao promover a primeira eleição para câmara dos vereadores e instalação da vila Nossa Senhora da Luz dos Pinhais, depois Curitiba. Atualmente a capital paranaense conta com 1.851.215 habitantes (IBGE/2009) em uma área de 434,967 km² dividida em 75 bairros. Os números mostram que Curitiba se desenvolveu e agora enfrenta o desafio de grande metrópole, onde a questão urbana é repensada sob o enfoque humanista de que a cidade é primordialmente de quem nela vive. Por isso foi vista a necessidade de estabelecer meios de transmitir as informações da prefeitura para o seu público de maneira eficiente e que busque aproximar os cidadãos de suas ações. Segundo o site da Prefeitura de Curitiba, o seu povo acredita na arte da convivência e do encontro e, através das pessoas, renasce todos os dias com esperança de crescimento e prosperidade. 
A Prefeitura Municipal de Curitiba utiliza como instrumentos de relacionamento com a comunidade algumas estratégias de aproximação com os curitibanos; entre eles: a mídia online, televisiva, radiodifusão e impressa. As mídias online são ferramentas inovadoras e tecnológicas, que além de informar um grande número de pessoas, utilizam estratégias de integração entre elas. Nos dias atuais, a internet é a principal ferramenta de informação que abrange diferentes classes sociais e possibilita o acesso a todos. Por estes motivos, a Prefeitura optou por utilizar as seguintes mídias online: site institucional, facebook, twitter, youtube e instagram.

A primeira mídia analisada é o site institucional. A página conta com diferentes abas de serviços públicos, direcionando os usuários para os portais de seu interesse. Por exemplo: Secretaria Antidrogas, Secretaria de Defesa Civil e Secretaria de Educação. Nesta página principal, podem-se obter informações sobre todas as áreas públicas da cidade, sendo organizada por temas específicos, como: saúde, trânsito, habitação, trabalho e emprego, educação, transporte, meio ambiente, mulher, entre outros. Serviços básicos também são disponibilizados, como: impressão de IPTU, certidão negativa, e dívidas ativas. O objetivo é facilitar os procedimentos burocráticos. A área nobre da página é utilizada para notícias, como exemplos, utilizamos algumas chamadas: "Postes clandestinos são retirados do Centro", “Decreto regulamenta serviços de valet" e "Regional CIC discute LDO 2015”. As reportagens são de caráter público, sempre utilizam linguagem simples, imagens e fotos, que facilitam o entendimento da população. Alguns serviços também fazem parte da área nobre do site, são eles: serviços para o cidadão, serviços para a empresa, servidor, turista e transparência.

O site da Prefeitura Municipal de Curitiba apresenta uma linguagem simples e popular. Não busca a estrutura coloquial, mas de maneira prática aborda palavras e textos de fácil compreensão. Alguns serviços, como a categoria transparência, utiliza termos e linguagem técnica, pois são baseadas em despesas, receitas, contratos e licitações, que ficam disponíveis para prestação de contas, atendendo à Lei da Informação. Por se tratar de uma mídia com o objetivo de informar, que é de caráter público, e não focada na integração, o site institucional possui linguagem jornalística, representada pelas reportagens, materiais e boletins, e principalmente linguagem informativa, representada pelas palavras-chaves que direcionam o usuário aos serviços desejados. As imagens contidas no site da Prefeitura de Curitiba são, na maioria das vezes, atribuídas nas reportagens e matérias divulgadas pelo Órgão. Banners também são utilizados para indicar alguma informação quando o objetivo é destacar. O verde é a cor predominante no site, mas também visualizamos o amarelo, azul, vermelho e cinza. Todas 
adequadas na página de maneira discreta. O principal diferencial do site institucional da Prefeitura de Curitiba é a estruturação de toda a área de maneira clara e objetiva. As cores utilizadas destacam os principais serviços e as demais informações são colocadas de maneira harmônica na página. É um site fácil e claro de navegar, características indispensáveis nos princípios de comunicação pública porque o público de uma Prefeitura são os cidadãos, que são de todas as classes sociais, possuem culturas diferentes e estilos de vida diversificados.

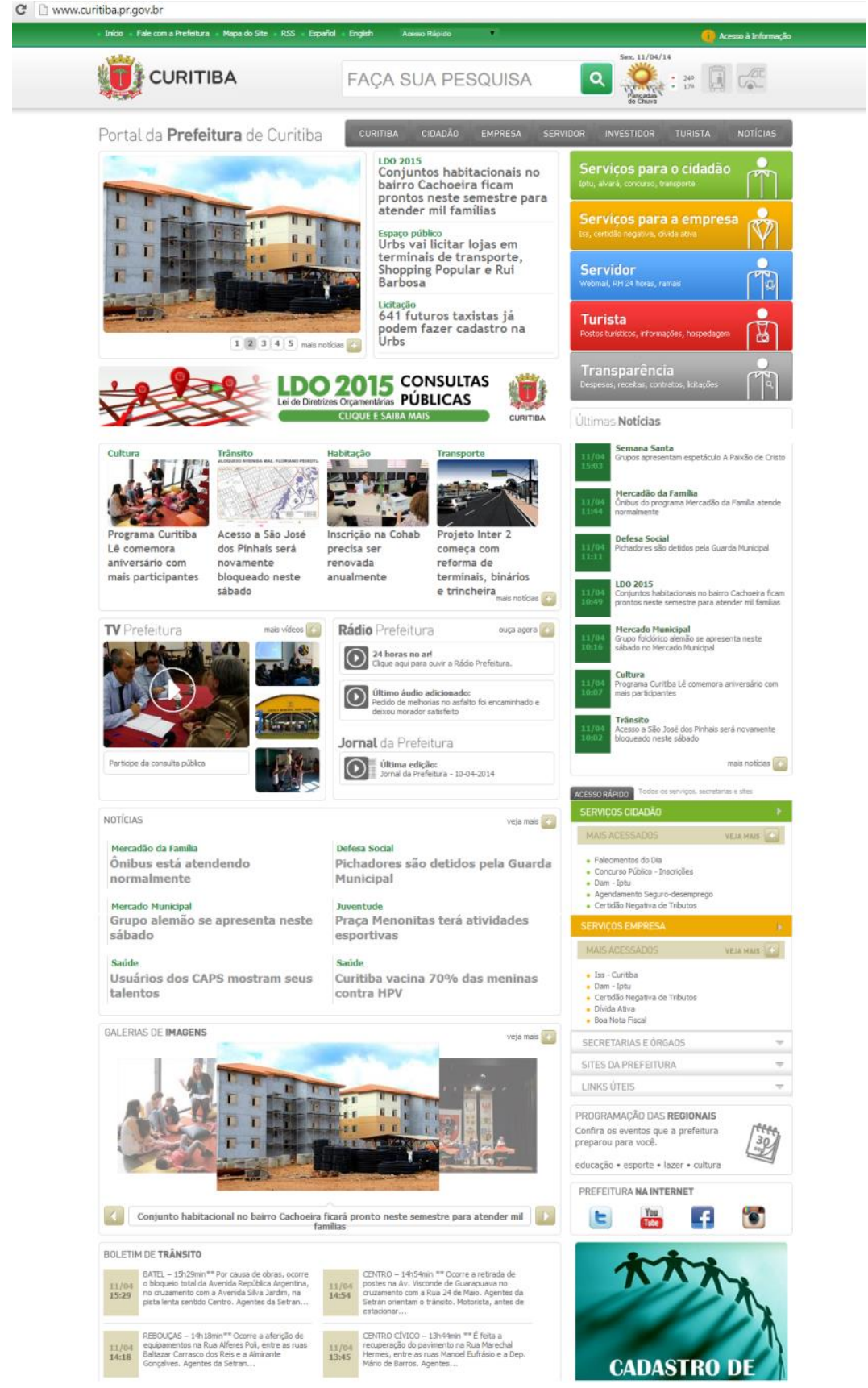

Figura 2 - Site Institucional da Prefeitura Municipal de Curitiba. 
A segunda mídia analisada é o espaço da Prefeitura de Curitiba na mídia social mais utilizada no mundo, segundo dados divulgados pela empresa de análise GlobalWebIndex, o Facebook. A Fanpage, como é chamada, é a que possui o maior número de seguidores entre todas as prefeituras do Brasil, totalizando 105.756 pessoas que curtiram a página, além de 92.758 pessoas que fazem parte do tópico "falando sobre isso", que se refere ao alcance das publicações, e 3.232 no tópico estiveram por aqui. A média de avaliações da página chega a 4,2, número que totaliza mais de 2.028 avaliações, entre eles, 1.354 votaram com cinco estrelas, considerando de um a cinco. Este resultado é orgânico, ou seja, nem $\mathrm{R} \$ 1,00$ foi pago para a conquista de fãs, sendo que o Facebook já declarou que dá preferência às empresas que pagam para tal integração, ao contrário da Prefeitura que conquistou seu público pela competência do conteúdo relevante. Os dados servem para diferenciar a página das demais em relação à integração, resultado do trabalho de disposição de conteúdos relevantes. A Fanpage da Prefeitura de Curitiba foi criada em 2013.

A página da Prefeitura de Curitiba no Facebook apresenta uma linguagem simples, lúdica, dinâmica, interativa e divertida. O foco da página é integrar e interagir, e por se tratar de uma mídia relativamente nova e ao mesmo tempo com um percentual alto de adeptos, sua linguagem é jovial. As postagens possuem tanto caráter sério, com informações relevantes e de utilidade pública, como incentivo às leis, a conservação do meio ambiente, ou, inclusive, postagens com linguagem criativa, engraçada e simpática. Fator responsável pelo diferencial da página. As postagens foram utilizadas para analisar e comprovar o estudo de linguagem e conteúdo, como alguns conteúdos disponibilizados:

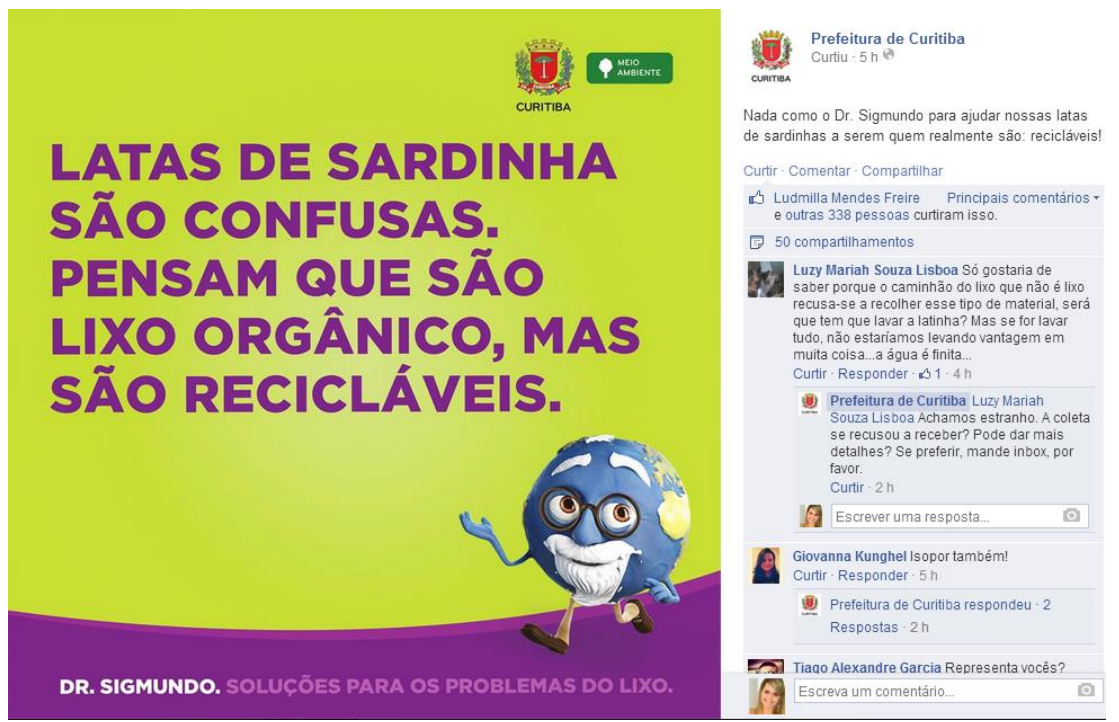

Figura 3 - Postagem da Prefeitura de Curitiba pelo Facebook falando sobre a conscientização da separação de lixo. 


\section{COMEÇA AGORA}

CONSULTA PÚBLICA NA REGIONAL DO BOA VISTA

\section{FACA SUA SUGESTÃO}

OU TIRE SUAS DÚVIDAS DA LDO 2015

LOCAL: CENIRO PASTORAL JOÃO PAULO II

RUA GUIUHERMEIHLENFEIDT, 1040 - TINGUI

HORARIO: 19:00 - 21:00
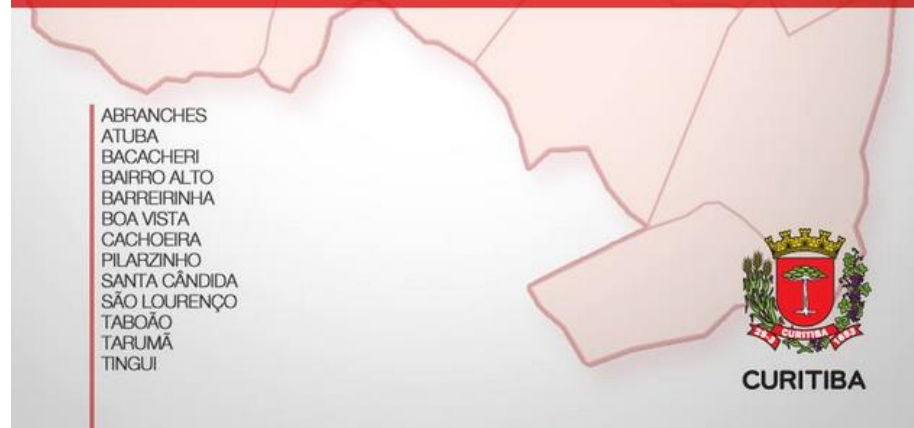

Prefeitura de Curitiba Cutiut 21 a

Figura 4 - Postagem da Prefeitura de Curitiba pelo Facebook falando sobre um evento público sobre a cidade.

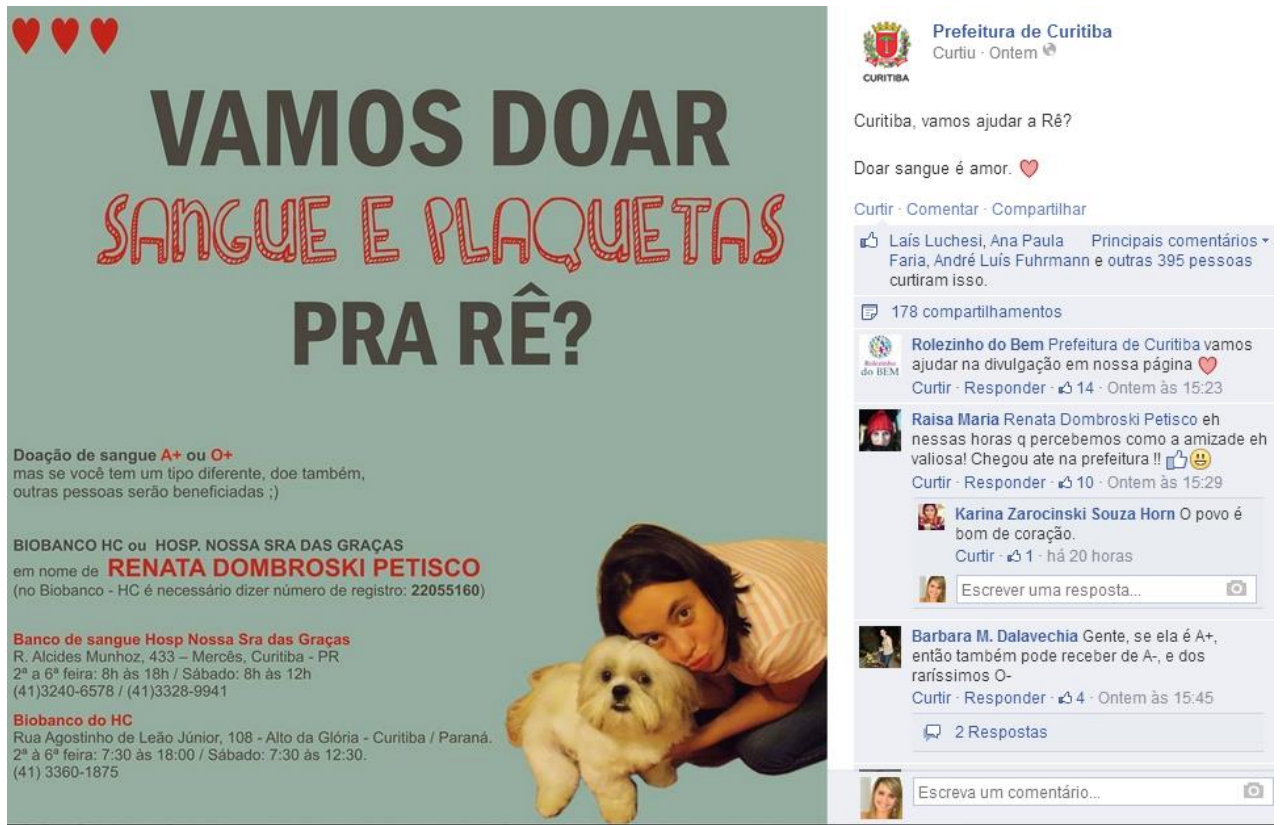

Figura 5 - Postagem da Prefeitura de Curitiba pelo Facebook falando sobre a doação de plaquetas. 

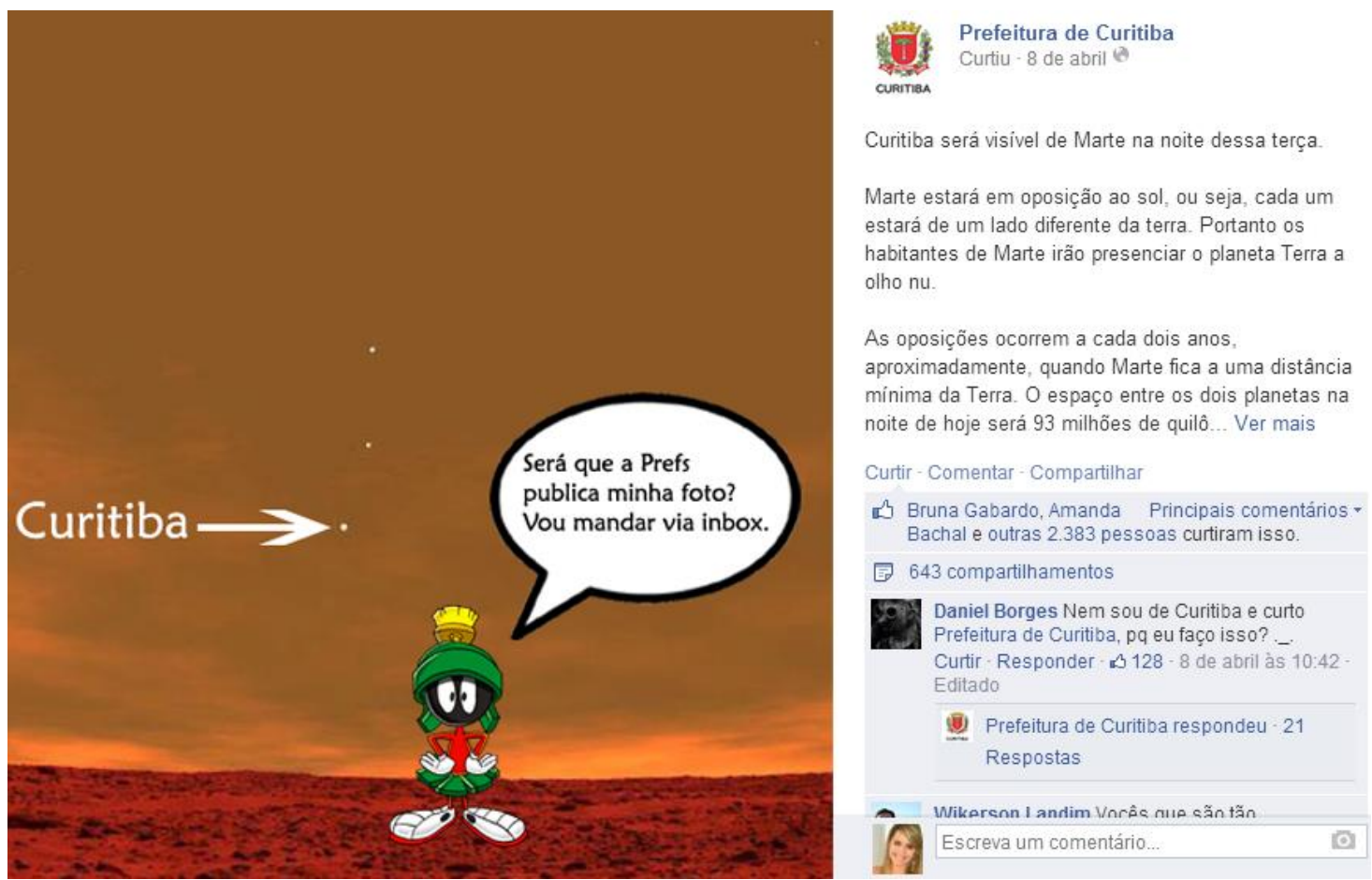

Figura 6 - Postagem da Prefeitura de Curitiba pelo Facebook falando sobre a posição de Marte e da Terra, de maneira lúdica.

A Prefeitura de Curitiba não possui uma página própria na rede youtube, mas, verificamos a presença de vários vídeos sobre o órgão. As publicações variam de propagandas institucionais a notícias sobre a cidade e seus serviços. Os vídeos são considerados "em alta" nas ferramentas de comunicação, porque transmitem informações de maneira rápida, prática, divertida e dinâmica. Conseguem repassar as informações necessárias a todo o seu público independente da classe social. O Twitter uma rede social e servidor para microblog, que permite aos usuários enviar e receber atualizações pessoais de outros contatos, por meio do website do serviço, por SMS e por softwares específicos de gerenciamento. As mensagens enviadas através do programa podem ser enviadas com no máximo 140 caracteres, tornandoo assim uma ferramenta de rápida leitura e facilitando a informação dos usuários. A página da Prefeitura Municipal de Curitiba conta com 22,2 mil seguidores e com 11,3 mil tweets.

\section{Considerações finais}

O propósito deste trabalho foi estudar e analisar a atuação do profissional de relações públicas dentro do processo de comunicação pública, através das mídias sociais da Prefeitura Municipal de Curitiba. Utilizamos como metodologia de pesquisa a análise de conteúdo disponibilizado na web, especificamente nas mídias sociais. A escolha do tema foi pautada pelo avanço da tecnologia e o surgimento das novas ferramentas de comunicação digital. Embasamos a teoria de como o profissional de relações públicas, em conjunto com as mídias 
sociais, pode auxiliar na comunicação pública, sendo uma ponte de ligação entre comunidade e prefeitura.

A partir da pesquisa sobre os temas apresentados e do órgão escolhido para análise, apuramos se os nossos questionamentos eram válidos. Percebemos a importância da qualidade de uma mídia social estruturada e focada estrategicamente na integração de uma população, além de ser voltada na valorização das informações em tempo real e disponibilizada de maneira coerente. Ao mesmo tempo, a mídia estudada busca um diferencial na conquista de seus seguidores, e acredita na troca de informações de maneira dinâmica, com utilização de uma linguagem amigável.

Com o sucesso das mídias sociais da Prefeitura de Curitiba, como foi verificado no estudo anterior, comprovamos a eficiência do profissional de relações públicas atuando no planejamento do projeto, e tendo como resultados a consolidação de uma comunicação estratégica, desenvolvida também dentro do processo de comunicação comunitária e governamental. A abordagem transmitiu credibilidade e reforçou ideias e informações, muitas vezes disponibilizadas de maneira ineficaz, que agora repercutem positivamente pelo ambiente em que atua. A atuação do profissional dentro da comunicação pública da Prefeitura fez com que o diálogo entre entidade governamental e população pudesse ser transformado de algo burocrático e extremamente distante para um exemplo de transparência, rapidez e eficiência. A linguagem utilizada e o conteúdo abordado fizeram com que a comunidade quisesse fazer parte da cidade de Curitiba, possibilitando uma comunicação mais integrada e fonte de ideias e inovação. A pesquisa reforça o papel do profissional de comunicação na gestão pública e fortalece a necessidade de adequar-se as novas tecnologias, pois cada vez mais é nesta ambiência que estes profissionais irão atuar para o desenvolvimento do relacionamento com o público.

(Artigo recebido em 29/10/2014, aprovado em 21/11/2014)

\section{Referências}

ANDRADE, Cândido Teobaldo de Sousa. Administração de relações públicas no governo. São Paulo: Loyola, 1982.

BARGER, Christopher. O Estrategista em Mídias Sociais: desenvolva um programa bemsucedido trabalhando de dentro para fora da sua empresa. São Paulo: DVS, 2013.

CIPRIANI, Fábio. Estratégia em Mídias Sociais. São Paulo: Elsevier Brasil, 2011.

DUARTE, Jorge. Comunicação Pública. São Paulo: Atlas, 2007. 
KUNSCH, Margarida Maria Krohling. Relações públicas comunitárias: a comunicação em uma perspectiva dialógica e transformadora. São Paulo: Summus, 2007.

OLIVEIRA, Lourdes Ivone de; MARCHIORI, Marlene. Redes Sociais, comunicação, organizações. São Paulo: Difusão, 2002.

NOVELLI, Ana Lucia. Relações Públicas Governamentais. In: Margarida M. K. Kunsch. (org.). Relações Públicas: história, teorias e estratégias nas organizações contemporâneas. São Paulo: Saraiva, 2009.

RUSCHEL, T. Orlando. Princípios da Comunicação Digital. Porto Alegre: Edipucrs, 1996.

SILVEIRINHA, Maria João. Comunicação política. Disponível em:> www.ifl.pt/main/Portals/0/dic/comunicao_politica.pdf $<$ Acesso: 24/11/2013.

TORQUATO, Gaudêncio. Tratado de Comunicação Organizacional e política. São Paulo: Pioneira Thomson, 2002.

Facebook da Prefeitura Municipal de Curitiba. Disponível em: $>$ www.facebook.com/prefeituradecuritiba $<$ Acesso em 01/03/2014.

Twitter da Prefeitura municipal de Curitiba. Disponível em: $>$ https://twitter.com/Curitiba_PMC $<$ Acesso em 01/03/2014. 